\title{
Analytical Method Development and Validation for Stability Indicating HPTLC Method for Assay of Stiripentol In Bulk and Dosage Form
}

\author{
Santosh Kumar Kashid*, Amit Tapkir, Pravin Choudhari
}

\begin{abstract}
This work is concerned with the stability-indicating method development and validation of Stiripentol in a bulk drug and formulation by high-performance thin-layer chromatographic method (HPTLC). The pre-coated silica gel $60 \mathrm{~F}_{254}$ aluminum plate was selected as the stationary phase, and the solvent system consisted of Ethyl acetate: Dichloromethane: Toluene (2:2:6 v/v) used as developing solvents. Analysis of Stiripentol was carried out at $301 \mathrm{~nm}$ with Stiripentol being detected at an R(f) of 0.63 . The developed method was validated for linearity, accuracy, precision, limit of detection (LoD), limit of quantitation (LoQ), robustness parameters, and stability are determined by force degradation study. The correlation coefficient of Stiripentol was 0.994 observed. The calibration plot was linear between 50-300 ng/band, respectively. The average percentage recovery of Stiripentol was found to be $100.25 \%$. Intra and inter-day precision measured as \%RSD was less than $2 \%$. Hence stability study of Stiripentol, it was found to degrade in acidic condition(8.52\% - $0.1 \mathrm{~N} \mathrm{HCL}$ for 30 minutes at room temperature), alkali condition(7.47\%- $0.1 \mathrm{~N} \mathrm{NaOH}$ for 30min at room temperature), Hydrolytic condition (4.73\%- dist. Water for $30 \mathrm{~min}$ at room temperature), thermal condition $\left(7.69 \%-40^{\circ} \mathrm{C}\right.$ for $\left.30 \mathrm{~min}\right)$, oxidative condition( $7.55 \%$ $3 \% \mathrm{H}_{2} \mathrm{O}_{2}$ for $30 \mathrm{~min}$ at room temperature) and photolytic UV condition(7.54\% - $24 \mathrm{hr}$ UV radiation) respectively. Stiripentol was unstable in acidic condition and stable in normal dist. Water hydrolytic condition. The proposed method was found to be very sensitive and accurate for the determination of Stiripentol in bulk and formulation.
\end{abstract}

Keywords: High-Performance Thin Layer Chromatography, Stiripentol, Stress degradation, Validation.

Journal of Applied Pharmaceutical Sciences and Research, (2020); DOI: 10.31069/japsr.v3i4.5

\section{INTRODUCTION}

Stiripentol is a newly approved antiepileptic drug ${ }^{[1,2]}$ (Figure 1). The racemic mixture of Stiripentol has two enantiomers $R(+)$ Stiripentol and S (-). ${ }^{[3]}$ Stiripentol of which R (+) has 2.4-fold greater anticonvulsant potency and 3 -fold faster elimination rate then S (-) Stiripentol. ${ }^{[4]}$ Its clinical development was delayed due to its inhibitory effect on hepatic cytochrome P450 (CYP)..$^{[5]}$ By suppressing GABA uptake, Stiripentol increases $\gamma$-GABA concentration in brain tissues and reduces GABA transaminase activity. ${ }^{[6]}$ Stiripentol has no affinity for $G_{A B A}$ and $G_{A B A}$ receptors. ${ }^{[7]}$ The European marketing authorization has approved Stiripentol for the treatment of Dravet syndrome or severe myoclonic epilepsy in infancy SMEl in combination with sodium valproate and clobazam. ${ }^{[8,9]}$

Pharmaceutical dosage form of Stiripentol is imperative for the optimum and efficient delivery of its therapeutic activity to the patients by stability testing. The motive of stability testing is to look into changes in the quality of a drug substance or a drug product with time due to

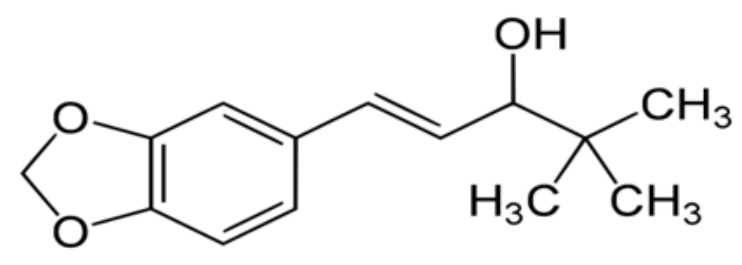

Figure 1: Structure of Stiripentol
PE's Modern College of Pharmacy, Nigdi, Pune, Maharashtra, India Corresponding Author: Santosh Kumar Kashid, PE's Modern College of Pharmacy, Nigdi, Pune, Maharashtra, India, Email: santoshkashid963@gmail.com

How to cite this article: Kashid SK, Tapkir A, Choudhari P. Analytical Method Development and Validation for Stability Indicating HPTLC Method for Assay of Stiripentol In Bulk and Dosage Form. Journal of Applied Pharmaceutical Sciences and Research. 2020; 3(4):26-30

Source of support: Nil

Conflict of interest: None

environmental factors, such as temperature, humidity, and light. Furthermore, stability testing includes storage conditions and shelf life for the drug product. ${ }^{[10,11]}$ In certain, pharmaceuticals are fundamentally sensitive to environmental conditions, which are usually varied during the different stages (i.e., manufacturing, transportation and storage) of the finished products. Based on the earlier mentioned importance of stability testing, it is essential to investigate degradation pathways and stability of the drug. Recently, the need to establish a stability-indicating assay method for stability testing has become more clearly mandated in the official guidelines at the International Conference on Harmonization $(\mathrm{ICH})^{[11]}$ and United States Pharmacopeia (USP). A detailed literature survey disclosed that only few high-performance liquid chromatography (HPLC) methods were reported to determine STP to study its

(๑) The Author(s). 2020 Open Access This article is distributed under the terms of the Creative Commons Attribution-NonCommercial-ShareAlike 4.0 International (CC BY-NC-SA 4.0) (https://creativecommons.org/licenses/by-nc-sa/4.0/) 
pharmacokinetics. ${ }^{[12]}$ It is important for the determination of Stiripentol in bulk and dosage form by a stability-indicating method by high-performance thin-layer chromatography (HPTLC).

Previously there is no research paper published on the stability-indicating assay method by HPTLC. So, it is necessary to validate and study degradation of stiripentol by stabilityindicating assay method by HPTLC.

\section{Material and Method}

\section{Chemicals and Reagents}

Stiripentol working standard of the pharmaceutical grade was gifted from NURAY CHEMICALS PVT. LTD, TAMILNADU and all chemicals and reagents such as methanol, toluene, ethyl acetate, dichloromethane, conc. hydrochloric acid, hydrogen peroxide, sodium hydroxide pellets of analytical grade were provided by the college.

\section{Instrumentation}

Chromatography was performed on $10 \times 10 \mathrm{~cm}$ Aluminum TLC plates $60 \mathrm{~F}_{254}$ precoated with $250 \mu \mathrm{m}$ layers of silica gel. Samples were applied in the form of bands, under a continuous flow of nitrogen, by means of a Camag Linomat $V$ (Switzerland) sample applicator fitted with $100 \mu \mathrm{L}$ applicator syringe. A constant application rate of $0.1 \mu \mathrm{L}$ per second was used and the distance between the adjacent bands were also optimized. The plates were then conditioned for 10 minutes in a presaturated twin-trough glass chamber $\left(10 \times 10 \mathrm{~cm}^{2}\right)$. The spotted plate was then dipped in mobile phase (Toluene: Dichloromethane: Ethyl acetate (6:2:2 v/v) and ascending development was performed to a distance of around 80 $\mathrm{mm}$ from the point of application at ambient temperature. Subsequently, plates were dried in a current of air with the help of an air dryer, and spots were visualized in Camag UV cabinet copper formed at $301 \mathrm{~nm}$ with Camag TLC scanner III operated in reflectance-absorbance mode and controlled by Win Cats software. The slit dimensions $(4 \times 0.2 \mathrm{~mm})$ were also optimized and kept constant throughout the analysis.

\section{Preparation of Standard and Construction of Calibration Curve}

The stock solution of Stiripentol was prepared by dissolving accurately about $5 \mathrm{mg}$ of Stiripentol with $10 \mathrm{~mL}$ methanol. Aliquots of this solution were suitability diluted with methanol to get working standard solutions of Stiripentol with a $500 \mu \mathrm{g} / \mathrm{mL}$ concentration. A calibration curve was plotted between concentrations against their respective area for Stiripentol. The calibration curve found that Stiripentol has a linearity range between 50-300 ng/spot.

\section{Results And Discussion}

\section{Method Development}

The HPTLC method was optimized for validation and method development of Stiripentol. The mobile phase Toluene:
Dichloromethane: Ethyl acetate (6:2:2 v/v) resulted in good resolution and sharp peaks of RF 0.63 for Stiripentol. It was observed that prewashing of TLC plates with methanol (followed by drying and activation) and pre-saturation of TLC chamber with mobile phase for 30 min (optimum chamber saturation time) ensured good repeatability (Figure 2).

\section{Method Validation}

The method was validated for linearity, accuracy, precision, LoD and LoQ, robustness study and stress degradation study.

\section{Linearity and Range}

For establishment of linearity of Stiripentol by proposed method, the calibration curve was obtained at five levels in the concentration range of 50-300ng/spot. The different increasing amounts of Stiripentol working standard (0.4 $\mathrm{mg} / \mathrm{mL}$ ) were spotted three times on individual plates and analyzed as described. The observed peak area and concentrations were subjected to least square regression analysis to calculate calibration equation and correlation coefficient for evaluation of linearity. The observed linearity confirming adherence of the system to Beer's law. The regression analysis equation was $y=345.7+16.03 * X$ with correlation coefficient ( $r$ ) was 0.99419 shown in Table 1.

\section{Precision}

Precision of the method was verified by repeatability and intermediate precision studies.

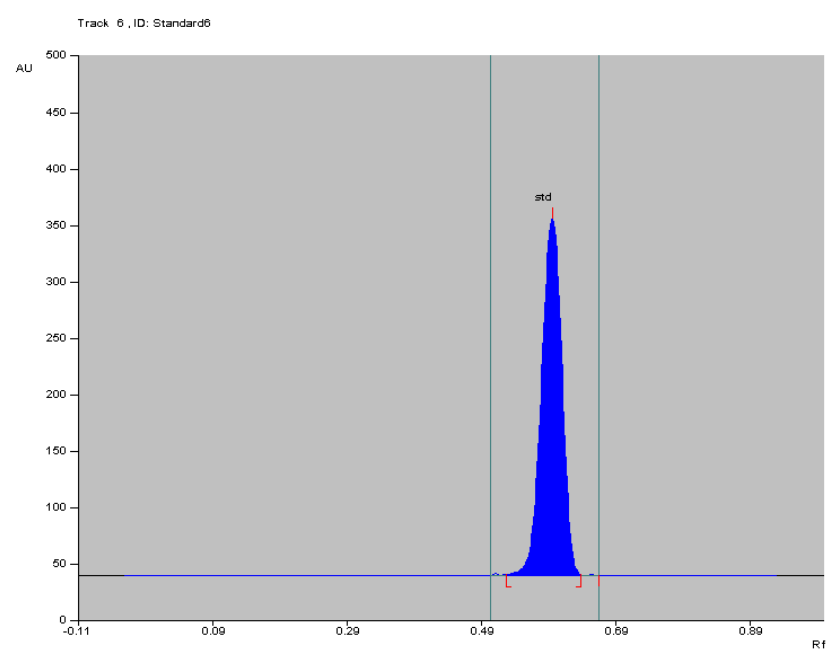

Figure 2: HPTLC densitogram of stiripentol

Table 1: Calibration curve of stiripentol

\begin{tabular}{llll}
\hline Sr. No. & Concentration (ng/band) & $R f$ & Area \\
\hline 1 & 50 & 0.64 & 1145.88 \\
2 & 100 & 0.63 & 2050.08 \\
3 & 150 & 0.63 & 2810.89 \\
4 & 200 & 0.63 & 3348.40 \\
5 & 250 & 0.63 & 4180.49 \\
6 & 300 & 0.63 & 5370.97 \\
\hline
\end{tabular}


Inherent stability study of Stiripentol by HPTLC method

Table 2: Repeatability result of stiripentol

\begin{tabular}{|c|c|c|c|c|c|c|}
\hline Drug & Amount of drug taken & $\%$ mean estimated & S.D. & \%R.S.D & & \\
\hline \multirow[t]{3}{*}{ Stiripentol } & $4 \mathrm{mg}$ & 99.2 & 0.624 & 0.627 & & \\
\hline & $5 \mathrm{mg}$ & 99.5 & 0.493 & 0.494 & & \\
\hline & $6 \mathrm{mg}$ & 99.6 & 0.416 & 0.419 & & \\
\hline \multicolumn{7}{|c|}{ Table 3: Intermediate precision of stiripentol } \\
\hline Drug & Amount of drug taken & $\%$ Mean estimated & S.D. & \%R.S.D & & \\
\hline \multirow[t]{3}{*}{ Stiripentol } & $4 \mathrm{mg}$ & 99.4 & 0.493 & 0.494 & & \\
\hline & $5 \mathrm{mg}$ & 99.6 & 0.435 & 0.438 & & \\
\hline & $6 \mathrm{mg}$ & 99.7 & 0.416 & 0.417 & & \\
\hline \multicolumn{7}{|c|}{ Table 4: Accuracy results of stiripentol by HPTLC } \\
\hline \multirow[t]{2}{*}{ Level of recovery (\%) } & Amount of drug added (mg) & Amount of drug recovered ( $\mathrm{mg}$ ) & $\%$ Recovery & $\%$ Recovery Mean & $S D$ & $\% R S D$ \\
\hline & 4 & 4.01 & 100.25 & & & \\
\hline \multirow[t]{3}{*}{80} & 4 & 4 & 100 & 100.33 & 10.17 & 0.37 \\
\hline & 4 & 4.03 & 100.75 & & & \\
\hline & 5 & 5.01 & 100.2 & & & \\
\hline \multirow[t]{3}{*}{100} & 5 & 4.99 & 99.94 & 100.23 & 10.59 & 0.31 \\
\hline & 5 & 5.02 & 100.56 & & & \\
\hline & 6 & 6.01 & 100.26 & & & \\
\hline \multirow[t]{2}{*}{120} & 6 & 5.99 & 99.87 & 100.21 & 13.11 & 0.32 \\
\hline & 6 & 6.03 & 100.52 & & & \\
\hline
\end{tabular}

Table 5: Robustness results of stiripentol by HPTLC

\begin{tabular}{lll}
\hline Chromatographic changes & & \\
\hline Factor & Level & Rfvalues \\
\hline $\begin{array}{l}\text { Mobile phase composition } \\
\text { Ethyl acetate: Dichloromethane: toluene }(2: 2: 6)\end{array}$ & & Stiripentol \\
\hline 2:3:5 & \pm 0.1 & 0.59 \\
2:2:6 & 0 & 0.63 \\
2:1:7 & \pm 0.1 & 0.64 \\
\hline Amount of mobile phase $( \pm 1 \mathrm{ml})$ & & Stiripentol \\
\hline 09 & -1 & 0.62 \\
10 & 0 & 0.63 \\
11 & +1 & 0.62 \\
\hline Duration of chamber $( \pm 1$ min) & & Stiripentol \\
\hline 5 min & -5 min & 0.64 \\
10 min & 0 min & 0.63 \\
15 min & +5 min & 0.59 \\
\hline
\end{tabular}

\section{Repeatability}

In the repeatability studies, six replicates of one concentration of Stiripentol were prepared and spotted on HPTLC plate. From the obtained data, \%RSD of Stiripentol were found to be less than $2 \%$. The results of repeatability studies for Stiripentol shown in Table 2.

\section{Intermediate Precision}

In the intermediate precision studies, six replicates of one concentration were prepared and spotted on HPTLC plate for 3 consecutive days. From the obtained data, \%RSD of stiripentol was found to be less than $2 \%$. The intermediate precision results of Stiripentol are shown in Table 3.

\section{Accuracy}

The method's accuracy was determined by calculating the recovery of Stiripentol by the standard addition method at three concentration levels $(80 \%, 100 \%$ and $120 \%)$. The percentage recoveries of Stiripentol were found to be in the range of $98-102 \%$. The Accuracy results of stiripentol are shown in Table 4. The weight of the capsule powder taken is $6 \mathrm{mg}$.

\section{Limits of Detection and Quantitation}

The LoD was found to be 0.0174 and LoQ was found to be $0.053 \mathrm{ng} / \mathrm{spot}$ for Stiripentol.

\section{Robustness}

To evaluate the robustness of the proposed method, small but deliberate variations in the optimized method parameters such as a change in chamber saturation time, change in the composition of the mobile phase. This was studied to find out the robustness of the proposed method $\%$ RSD was found to be less than $2 \%$. The Robustness result of change in saturation time ( $\pm 5 \mathrm{~min})$ of Stiripentol. Change in Mobile phase composition ( $\pm 1 \mathrm{~mL}$ ) of Stiripentol is shown in Table 5.

\section{Forced Degradation Study of Stiripentol}

$5 \mathrm{mg}$ Stiripentol was separately transferred to six different $10.0 \mathrm{ml}$ volumetric flasks (Flask No. 1, 2, 3, 4,5 and 6) shown 
Inherent stability study of Stiripentol by HPTLC method

Table 6: The results of the stress degradation studies of stiripentol by HPTLC

\begin{tabular}{lllll}
\hline Sr. No. & Stress Condition & Temp and Time & Percent degradation & Rf Value of degraded product \\
\hline 1. & Acid $(0.1 \mathrm{~N} \mathrm{HCl})$ & Room temp for 30 min & $8.52 \%$ & $0.65,0.43$ \\
2. & Alkali $(0.1 \mathrm{~N} \mathrm{NaOH})$ & Room temp for 30min & $7.47 \%$ & $0.64,0.41$ \\
3. & Neutral $\left(\mathrm{H}_{2} \mathrm{O}\right)$ & Room temp for $30 \mathrm{~min}$ & $4.73 \%$ & $0.62,0.41$ \\
4. & Thermal & $40^{\circ} \mathrm{C}$ for 30 min & $7.69 \%$ & $0.64,0.42$ \\
5. & Oxide $\left(3 \% \mathrm{H}_{2} \mathrm{O} 2\right)$ & Room temp for 30min & $7.55 \%$ & $0.63,0.40$ \\
6. & Photolytic Degradation & $24 \mathrm{hr}$ & $7.54 \%$ & $0.63,0.42$ \\
\hline
\end{tabular}

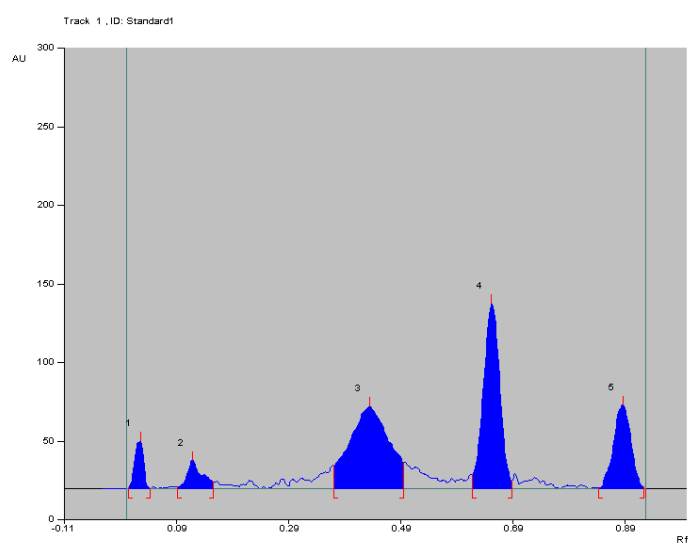

Figure 3: HPTLC Densitogram of acid degradation of stiripentol in $0.1 \mathrm{~N} \mathrm{HCl}$ at room temperature after $30 \mathrm{~min}$.

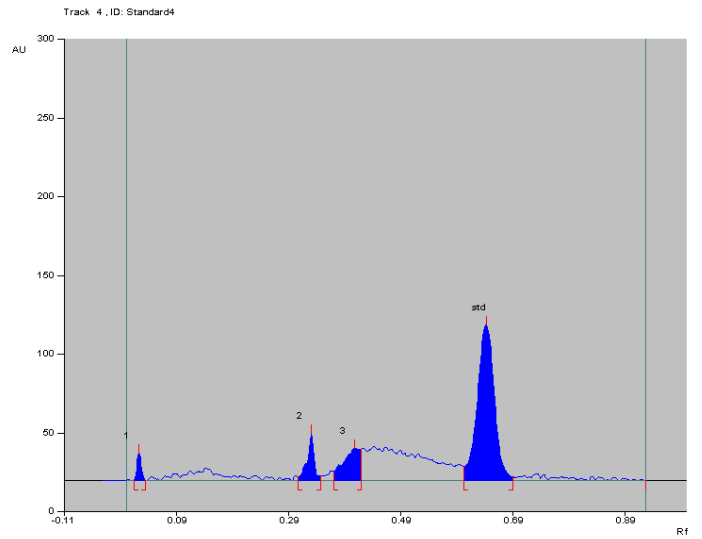

Figure 4: - HPTLC Densitogram of alkaline degradation of stiripentol in $0.1 \mathrm{~N} \mathrm{NaOH}$ at room temperature after $30 \mathrm{~min}$.

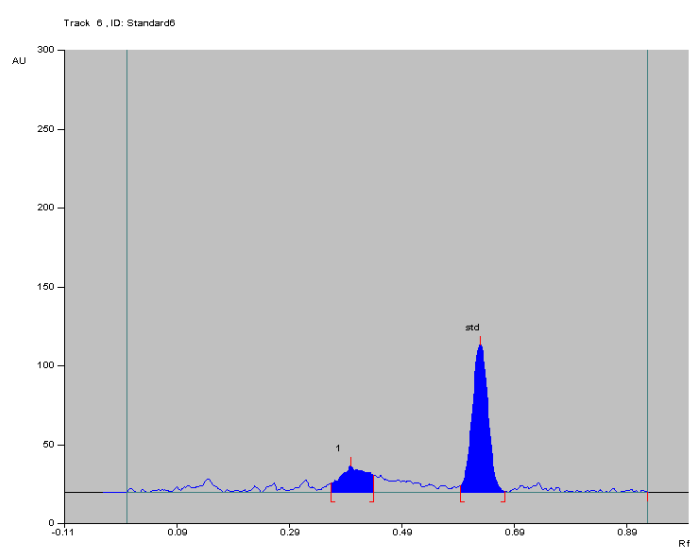

Figure 5: HPTLC Densitogram of oxidative degradation of Stiripentol in $3 \% \mathrm{H} 2 \mathrm{O} 2$ at room temperature after 30 mins.

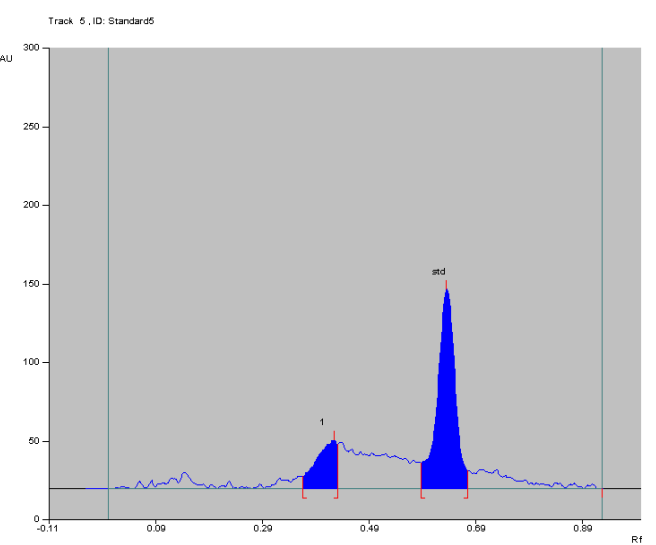

Figure 6: - HPTLC Densitogram of photolytic degradation of stiripentol on exposure to UV light for $24 \mathrm{hrs}$.

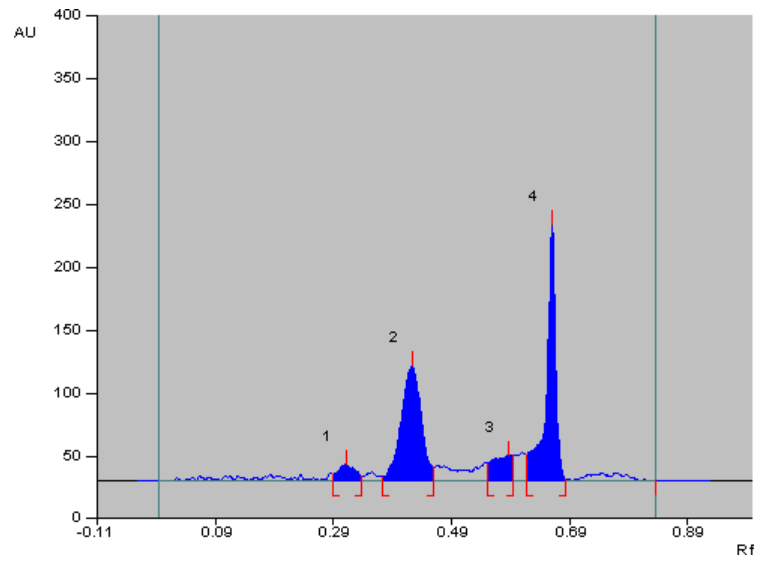

Figure 7: HPTLC Densitogram of thermal degradation of stiripentol on exposure to $40^{\circ} \mathrm{C}$ for $30 \mathrm{~min}$.

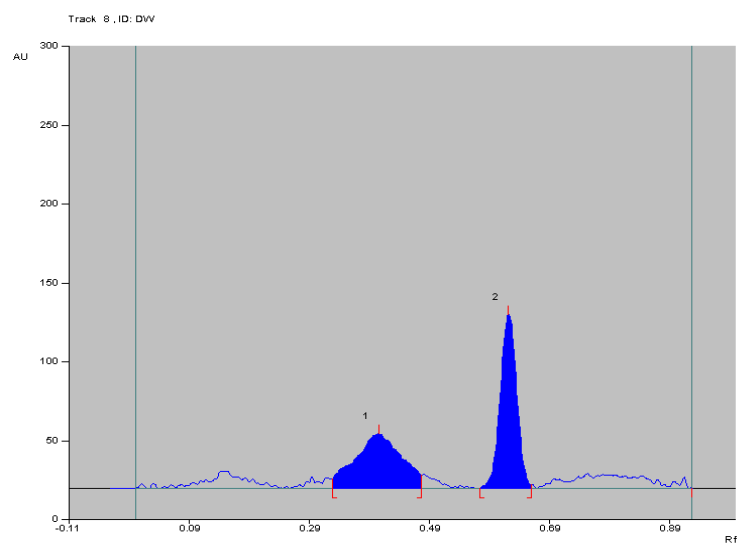

Figure 8: - HPTLC densitogram of Hydrolytic degradation of stiripentol in distilled Water at room temperature after $30 \mathrm{~min}$. 
in Table 6, added $3.0 \mathrm{ml}$ of $0.1 \mathrm{~N} \mathrm{HCl}, 0.1 \mathrm{~N} \mathrm{NaOH}, \mathrm{H}_{2} \mathrm{O}$ to Flask No. 1, 2, 3 respectively. In flask No. 4, $3 \% \mathrm{H}_{2} \mathrm{O}_{2}$ is added and kept at dark for 30 min. Flask No. 1, 2, 3 were kept at room temperature for $30 \mathrm{~min}$. Flask No. 5 containing Stiripentol was kept at $40^{\circ} \mathrm{C}$ for 30 min to study the effect of heat on drug sample (heat degradation). The forced degradation was performed in the dark to exclude the possible degradative effect of light. Flask No.6 was exposed to ultraviolet radiations at $254 \mathrm{~nm}$ for $24 \mathrm{hrs}$ in a UV- chamber. All the flasks were removed, the Stiripentol samples were treated and analyzed in similar manner as described under analysis of pure drug. The typical densitogram for acidic, alkali, oxide, neutral, heat and UV exposure, are shown in Figure 3-8.

\section{Discussion and Conclusion}

The HPTLC method was developed on precoated silica gel using Toluene: Dichloromethane: Ethyl acetate (6:2:2 $\mathrm{v} / \mathrm{v})$ as mobile phase with densitometric detection at 301 $\mathrm{nm}$. This study found that HPTLC method development for determination of Stiripentol in bulk and dosage form is accurate, precise, linear, highly sensitive, and robust. The force degradation study concludes that Stiripentol is most labile to acid hydrolysis followed by thermal degradation. The proposed degradation study is sensitive, precise, accurate, and stability-indicating, resolving all the drug's degradation products. Force degradation studies play an important role in the development of pharmaceuticals. The results of degradation studies help in the development of a stability-indicating method. The ICH Q1A guideline states that the validated stability-indicating test methods must be performed to monitor the shelf life of drug substances that are susceptible to change during storage and are likely to affect the quality, safety, and efficacy of the formulation.

\section{Units of Measurement}

$\begin{array}{lll}\text { Sr. No } & \text { Terms } & \text { Full forms } \\ \text { 1. } & \text { Conc. } & \text { Concentration } \\ \text { 2. } & \text { gm } & \text { Gram } \\ \text { 3. } & \text { lit. } & \text { Liter } \\ \text { 4. } & \mu \mathrm{l} & \text { microliter } \\ \text { 5. } & \mathrm{m} . \mathrm{mol} & \text { Milli molar } \\ \text { 6. } & \text { PPM } & \text { Parts per millions } \\ \text { 7. } & \mathrm{ng} & \text { Nanometers } \\ \text { 8. } & \lambda & \text { Wavelength } \\ \text { 9. } & \text { hrs } & \text { Hours } \\ \text { 10. } & \text { ng/band } & \text { Nano gram per band } \\ \text { 11. } & \text { UV } & \text { Ultraviolet } \\ \text { 12. } & \text { HPTLC } & \text { High Performance Thin Layer } \\ & & \text { Chromatography } \\ \text { 13. } & \text { SD } & \text { Standard deviation }\end{array}$
14. RSD
Relative Standard Deviation
15. LOD
Limit of detection
16. LOQ
Limit of Quantification
17. $\mathrm{Rf}$
Retention factor
18. DP'S
Degradation product

\section{References}

1. M. K. Trojnar, K. Wojtal, M. P. Trojnar, and S. J. Czuczwar, "Stiripentol. A novel antiepileptic drug," Pharmacological Reports, vol. 57, no. 2, pp. 154-160, 2005.

2. J.N. Lisgarten and R.A. Palmer, "The structure of Stiripentol: 4,4 dimethyl- 1-(3,4-methylenedioxyphenyl)-1-penten3-ola novel antiepileptic drug," Acta Crystallographic, Section C: Crystal Structure Communications, vol. 44, pp. 1992-1994, 1988.

3. D. F. Chollet, "Determination of antiepileptic drugs in biological material," Journal of Chromatography B: Analytical Technologies in the Biomedical and Life Sciences, vol. 767, no. 2, pp. 191-233, 2002.

4. D. D. Shen, R. Levy, J. L. Savitch, A. V. Boddy, F. Tombret, and F. Lepage, "Comparative anticonvulsant potency and pharmacokinetics of (+)-and (-)-enantiomers of Stiripentol," Epilepsy Research, vol. 12, no. 1, pp. 29-36, 1992.

5. J. L. Fisher, "The effects of Stiripentol on GABAA receptors," Epilepsia, vol. 52, no. 2, pp. 76-78, 2011.

6. Wegmann R, llies A, Aurousseau M, Pharmaco-cellular enzymology of the mechanism of action of Stiripentol in cardiazol-induced epilepsy. III. Protein, nucleoprotein, lipid, and proteoglycan metabolism, Cell Mol Biol Incl Cyto Enzymol, 1978, 23, 455-480.

7. M. Poisson, F. Huguet, A. Savattier, F. Bakri-Logeais, and G. Narcisse, "A new type of anticonvulsant, Stiripentol. Pharmacological profile and neurochemical study," ArzneimittelForschung, vol. 34, no. 2, pp. 199-204, 1984.

8. E. C. Wirrell, L. Laux, D. N. Franz et al., "Stiripentol in Dravet syndrome: results of a retrospective US study," Epilepsia, vol. 54, no. 9, pp. 1595-1604, 2013.

9. European Medicines Agency, "Stiripentol: Scientific Discussion," http://www.ema.europa.eu/docs/en GB/document library/ EPAR Scientific Discussion/ human/000664/WC500036521.pdf.

10. The United States Pharmacopeia (USP) 24th version, United States Pharmacopeial Convention, Rochville, Md, USA, 2000.

11. ICH Guidance for Industry, Q1A (R2): Stability Testing of New Drug Substances and Products (Revision 2), U.S. Department of Health and Human Services, Food and Drug Administration, Center for Drug Evaluation and Research (CDER), Center for Biologics Evaluation and Research (CBER), Rockville, Md, USA, 2003.

12. H. S. Lin and R. H. Levy, "Pharmacokinetic profile of a new anticonvulsant, Stiripentol, in the rhesus monkey," Epilepsia, vol. 24, no. 6, pp. 692-702, 1983. 